\title{
Microstructure and Reactivity of Supported Bimetallic Platinum-Gold Catalysts
}

\author{
Amit Sachdev and Johannes Schwank \\ Department of Chemical Engineering, The University of Michigan, Ann Arbor, Michigan 48109-2136
}

Received April 20, 1989; revised July 18, 1989

\begin{abstract}
In this paper an attempt is made to correlate the microstructure of a supported bimetallic catalyst system with its activity and selectivity. A series of bimetallic platinum-gold catalysts supported on high-surface-area nonporous Aerosil was prepared by the incipient wetness technique. The platinum-gold system is known to be partially miscible in the bulk with the possibility of alloy formation at high and low Pt/Au atomic ratios. The reducibility of the various metal components in these catalysts was determined by temperature-programmed reduction. Microstructural characterization of the catalysts was performed by using analytical and high-resolution electron microscopic techniques. The combination of elemental analysis by EDX and lattice fringe imaging by HREM of individual metal particles was used to determine the presence and location of the various components of this bimetallic system. The kinetic behavior for the $n$-hexane conversion reaction and the product selectivities toward dehydrocyclization, isomerization, and hydrogenolytic cracking were measured. The product selectivity trends in $n$-hexane conversion can be attributed mainly to geometric effects related to the relative distribution and interdispersion of the platinum and gold atoms in the catalysts. 1989 Academic Press, Inc.
\end{abstract}

\section{INTRODUCTION}

This study is part of an ongoing effort in our laboratory to examine the microstructure of supported bimetallic catalyst materials with special emphasis on the metal particles, and to correlate this information with the catalytic behavior. Previous microstructural characterization efforts of this nature have primarily concentrated upon systems such as $\mathrm{Ru}-\mathrm{Au}$ and $\mathrm{Ru}-\mathrm{Cu}$ whose two metallic components are immiscible in the bulk $(1,2)$. The $\mathrm{Pt}$-Au bimetallic system, on the other hand, exhibits a miscibility gap between 18 and 98 at.\% platinum (3). It is believed that the alloy formed between a Group VIII metal such as platinum and a IB element, such as Au, alters the catalytic behavior relative to that of the monometallic Pt catalyst. Improved selectivity toward desired products as well as a decreased rate of deactivation are some of the beneficial aspects of these alloy catalysts.

A major question in the study of these types of supported bimetallic catalysts is the location and presence, if any, of the alloy within the metal particles. In the case of the Au-Pt system, the bulk phase diagram dictates the presence of an $\mathrm{Au}_{3} \mathrm{Pt}$ solid solution. If this alloy is present, the contribution of the various components in the catalyst to the overall reaclive and adsorplive nature of the material needs to be determined. It is often tacitly assumed that bimetallic particles are alloys as long as the bulk compositional ratio of $\mathrm{Pt}$ : Au corresponds to the alloy region of the phase diagram.

It is one of the objectives of this study to test whether or not this assumption is indeed justified. A detailed microstructural and catalytic evaluation of supported $\mathrm{Pt}-$ Au catalysts was carried out. The catalysts were supported on a nonporous Aerosil silica and subjected to a typical catalyst characterization protocol including BET surface area, X-ray diffraction, XPS, chemisorption, infrared spectroscopy, and neutron activation. Temperature-programmed reduction (TPR) experiments 
were performed to determine the reducibility of the various components in these catalysts. The catalytic activities and the selectivities toward dehydrocyclization, isomerization, and cracking products were measured for the $n$-hexane conversion reaction. Finally, electron microscopy investigations were performed on these very same metal catalysts. The typical metal particle size of these supported bimetallic catalysts ranges from as small as $0.5 \mathrm{~nm}$ to as large as $40 \mathrm{~nm}$. The analysis of metal particles smaller than about $5 \mathrm{~nm}$, the size range where most of the interesting catalysis takes place, is an especially difficult task. Traditionally, such an analysis has been carried out primarily by using a dedicated STEM instrument with a field emission gun which is capable of forming an electron probe as small as $0.5 \mathrm{~nm}$. With this method, qualitative elemental analysis of small particles can be accomplished through energy dispersive analysis of the characteristic X-rays emitted from the area irradiated by the electron beam. This method, however, is not suitable to generate structure images of close-packed metal lattices at atomic resolution. Our approach was to directly obtain structure images of individual small metal particles by high-resolution TEM and to derive the composition and structure of the particles from the lattice fringe spacings. In addition, analytical electron techniques such as EDX and microdiffraction were employed in providing the complementary data from some of the larger metal particles in our catalysts.

Previously, many of the high-resolution electron microscopy studies of small metal particles have been performed using idealized or model specimen preparation techniques. Here, we examined under the microscope the very same specimens that were used in the catalytic experiments. In this way one does not have to deal with the unknowns present in extrapolating the characterization information from an ideal specimen to the kinetic results of the actual catalyst. By mapping out the relative con- tribution of metal particles of different sizes and structures in a given catalyst, a clearer interpretation of the kinetic results in test reactions such as hexane conversion as a function of catalyst microstructure can be obtained.

Several studies of the Pt-Au system have been performed on supported catalysts as well as on single crystals. Sachtler and Somorjai (4) found an ensemble effect in the $n$ hexane conversion reaction over $\mathrm{Au}-$ $\mathrm{Pt}(111)$ bimetallic single-crystal surfaces. The relative distribution of the epitaxial $\mathrm{Au}$ layers on the $\mathrm{Pt}(111)$ single crystal influenced the product distribution toward reactions which have a tendency to proceed over smaller ensemble sizes. With increasing $\mathrm{Au}$ loading the selectivity toward isomerization increased. Similar experiments over $\mathrm{Pt}(100)$ and $\mathrm{Pt}(111)$ single-crystal surfaces indicated that the isomerization reaction was structure sensitive. A comparison of temperature-programmed desorption of hydrogen from $\mathrm{Pt}$ and $\mathrm{Pt}-\mathrm{Au}$ films showed no shift in the hydrogen desorption peak but only a small change in intensity (5). The authors explained these intensity changes as primarily due to the geometric relationship between the platinum and gold entities and all but ruled out any charge transfer between the various components of the catalyst. The catalytic trends for the skeletal reactions of neopentane over platinumgold catalysts were attributed to the different types of platinum ensembles for various gold contents (6). Numerous experiments have also determined that there tends to be a higher concentration of gold at the surface than in the bulk of platinum-gold thin films (7-9).

\section{EXPERIMENTAL}

I. Materials. Four catalysts were prepared in the platinum-gold series with Aerosil 200 (surface area $=200 \mathrm{~m}^{2} / \mathrm{g}$ ) used as the support. Monometallic $1 \mathrm{wt} . \% \mathrm{Pt} /$ $\mathrm{SiO}_{2}$ and $2 \mathrm{wt} \% \mathrm{Au} / \mathrm{SiO}_{2}$ as well as the bimetallic $1 \mathrm{wt} \% \mathrm{Pt}-0.3 \mathrm{wt} \% \mathrm{Au} / \mathrm{SiO}_{2}$ and 1 
wt $\% \mathrm{Pt}-0.7 \mathrm{wt} \% \mathrm{Au} / \mathrm{SiO}_{2}$ composed the serics. The bimetallic samples in this scrics will, hereafter, be referred to as $0.3 \mathrm{Au}$ and $0.7 \mathrm{Au}$, respectively. The supported catalysts were prepared by the incipient wetness technique with aqueous solutions of hexachloroplatinic acid and chloroauric acid. The bimetallics were prepared by coimpregnation. The catalysts were dried at $393 \mathrm{~K}$ in a stream of purified air followed by reduction under flowing hydrogen at 673 $\mathrm{K}$ for $16 \mathrm{~h}$.

2. Procedure. The $n$-hexane conversion reactions were conducted in a continuous flow reactor under atmospheric pressure and at a temperature range of 503-583 K which was sufficient to keep the conversion at around $20 \%$ or less. Catalyst powder (1 g) was placed in a 12-mm-id Pyrex glass reactor and held between plugs of glass wool. Fluka purissimum hexane was used as a reactant. The hydrogen, which was purified using a Matheson palladium hydrogen purifier, was passed at a flow rate of $20 \mathrm{ml} /$ min though a hexane saturator situated in an ice bath maintained at $273 \mathrm{~K}$. The final hexane to $\mathrm{H}_{2}$ ratio was $1 / 16$ and the molar flow rate through the catalyst bed was 0.74 mol hexane/g of catalyst/h. The calculations of overall conversion, $X$, and selectivities were done according to the method of Ponec and Sachtler (10). The product selectivities were classified into three groups, namely, cyclization (formation of methylcyclopentane and benzene), isomerization (formation of 2-, 3-methylpentane), and cracking (formation of $\mathrm{C} 1-\mathrm{C} 5$ paraffins). Blank runs with the empty reactor and with plain $\mathrm{SiO}_{2}$ support which had undergone a mock impregnation and pretreatment procedure did not show any measurable activity under reaction conditions.

Temperature-programmed reduction was performed on air-dricd, unreduced catalyst samples in an apparatus described previously (11). Briefly, $100 \mathrm{mg}$ of sample was inserted into a quartz tube and heated at a rate of $10 \mathrm{~K} / \mathrm{min}$ under a flow of $3 \% \mathrm{H}_{2} / \mathrm{N}_{2}$ (Alphagaz Research Grade). Traps of mo- lecular sieve maintained at dry ice temperatures were placed before and after the reactor loop to prevent any moisture from affecting the TCD output signal. The TPR profiles could be quantitatively analyzed by measuring the area under the peaks and comparing this value with a calibrated peak area.

3. Electron microscopy. Electron microscopic investigations were done in two stages. The analytical segment was carried out in a JEOL $2000 \mathrm{FX}$ operated at $200 \mathrm{kV}$. The elemental composition of metal particles was determined by using energy dispersive spectroscopy (EDX) with a stationary TEM probe. In addition, structural information was derived from particles as small as $6 \mathrm{~nm}$ from microdiffraction patterns which could be obtained by also using a very small stationary electron probe. However, to examine the structure and composition of the particles smaller than 6 $\mathrm{nm}$, high-resolution electron microscopy (HREM) became necessary. The HREM work for this project was accomplished on a JEOL-4000EX operating at $400 \mathrm{kV}$ and equipped with a top entry stage goniometer. The microscope was directly interfaced with a Macintosh II computer with image processing capabilities to enable real time image calculations. The specimens for electron microscopy were prepared by gently grinding the powder sample in an agate mortar, suspending and sonicating in isopropanol, and subsequently placing a drop or two on a holey carbon copper grid.

To determine the lattice spacings accurately from very small metal particles, optical diffractograms of the structure images were obtained by utilizing an optical bench equipped with a $4 \mathrm{~mW}$ He-Ne laser (Spectra Physics). The distances on the diffractograms were calibrated using a Si $\langle 111\rangle$ specimen (obtained from AT\&T Bell Laboratories), whose $\{220\}$ lattice spacings measure $0.192 \mathrm{~nm}$. Great care was taken in ensuring high accuracy and it was estimated that the worst case error in the $d$ spacing measurements was $\pm 2 \%$. The factor which contrib- 
uted the most to this error was the finite size of the diffraction spots.

\section{RESULTS}

\section{1. n-Hexane Conversion}

The temperature versus selectivity plots are shown in Fig. 1. The catalyst with the highest gold content, i.e., $0.7 \mathrm{Au}$, had the highest propensity toward the formation of methylpentanes. It has been well documented in the literature that isomerization reactions require the smallest platinum ensembles with the dehydrocyclization and cracking reactions needing progressively larger groups of adjacent platinum sites $(12-14)$. So with increasing dilution of the platinum sites by inactive Au the resulting smaller ensembles of $\mathrm{Pt}$ favor isomeric products. The isomerization reaction on the $0.7 \mathrm{Au}$ catalyst probably proceeds through a cyclic intermediate or a carbonium ionlike intermediate. The latter route takes place on only the highly diluted regions of the sample containing very small platinum ensembles which may even be single sites $(13,15)$.

At first sight, the selectivity trends for the $0.3 \mathrm{Au}$ catalyst appear to contradict the above hypothesis. If the previously described geometric model were applicable, one would expect the $0.3 \mathrm{Au}$ sample to also have a lower cracking selectivity than the monometallic $\mathrm{Pt} / \mathrm{SiO}_{2}$. Instead, the opposite was true. We observed a higher cracking selectivity in the $0.3 \mathrm{Au}$ catalyst compared to monometallic platinum, which was surprising as one would expect a gold-induced suppression of cracked products. In addition, the dehydrocyclization selectivities for the monometallic Pt catalyst were higher than those of the bimetallic catalysts. The relative trends in the isomerization selectivity between the $0.3 \mathrm{Au}$ and the monometallic $\mathrm{Pt} / \mathrm{SiO}_{2}$ were inconclusive.

We suspected that the key to this apparent contradiction might be related to differences in particle size and composition, and consequently, different effects of gold on
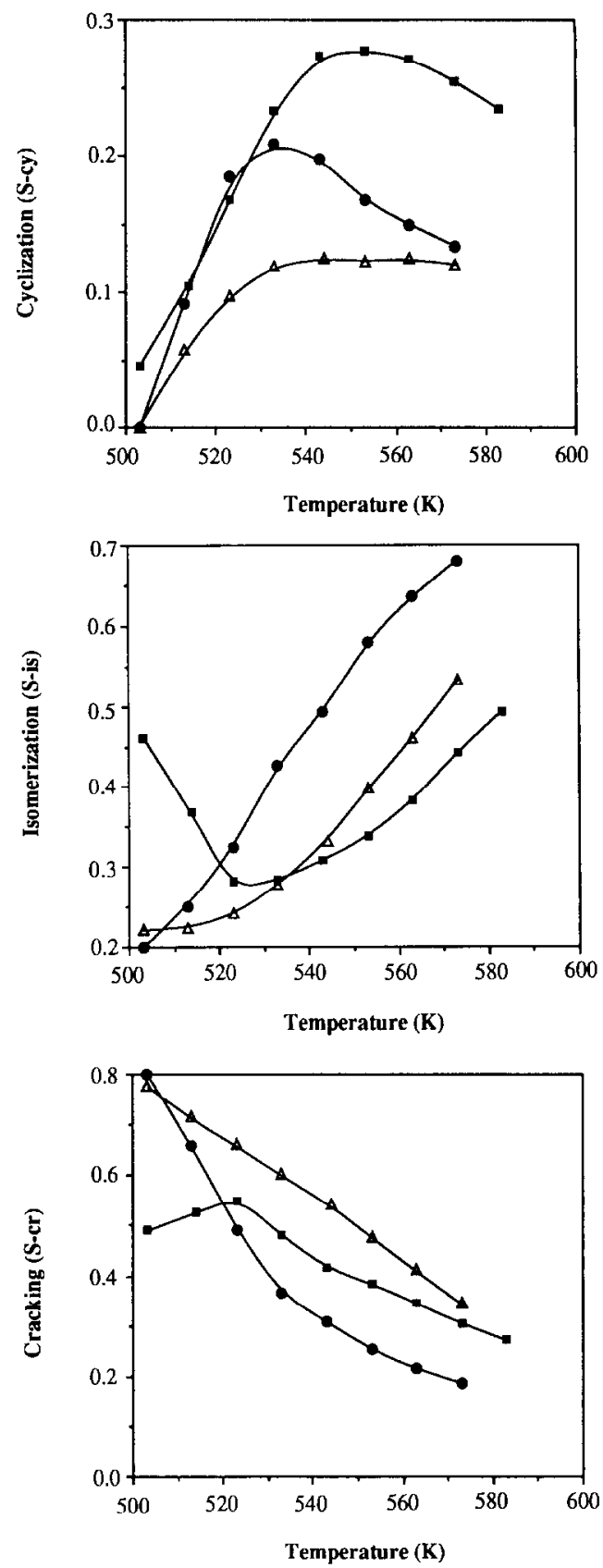

FIG. 1. Temperature versus selectivities toward dehydrocyclization, isomerization, and cracking. (更 1.0 $\mathrm{Pt} / \mathrm{SiO}_{2},(\triangle) 1.0 \mathrm{Pt}-0.3 \mathrm{Au} / \mathrm{SiO}_{2}$, (O) $1.0 \mathrm{Pt}-0.7 \mathrm{Au} /$ $\mathrm{SiO}_{2}$.

the platinum ensemble size. Obviously, a detailed microstructural characterization is necessary to elucidate the reasons for this discrepancy. 


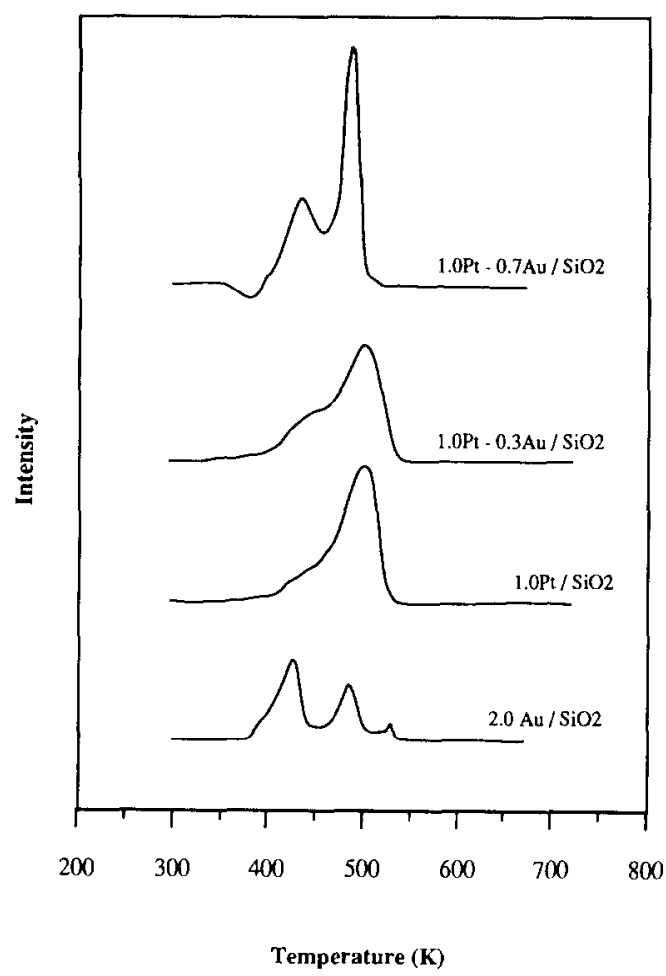

FIG. 2. Temperature-programmed reduction profiles on fresh unreduced catalysts.

\section{Temperature-Programmed Reduction}

An additional indication that there are significant differences between the calalysts in the $\mathrm{Pt}-\mathrm{Au}$ series comes from the TPR results. The temperature-programmed reduction profiles are useful in identifying and evaluating the reducibility of the various components in a catalyst sample. The TPR plots in Fig. 2 illustrate the hydrogen consumption peaks of the fresh, unused catalysts as a function of temperature, thereby tracking the genesis of reduced metal particles on the surface of the $\mathrm{SiO}_{2}$ support.

The monometallic $\mathrm{Pt} / \mathrm{SiO}_{2}$ had a single reduction peak at $503 \mathrm{~K}$. The reduction peak represents the conversion of the precursor, chloroplatinic acid, into zero valent platinum. The $2.0 \mathrm{Au} / \mathrm{SiO}_{2}$ showed the main reduction peak at $413 \mathrm{~K}$ and two minor peaks at 488 and $528 \mathrm{~K}$. This latter peak most probably is due to the sublimation of chloroauric acid as $\mathrm{AuCl}_{3}$ (16), while the other minor peak at $488 \mathrm{~K}$ could be caused by the formation kinetics of gold particles with wide size distributions.

The bimetallic $1.0 \mathrm{Pt}-0.3 \mathrm{Au} / \mathrm{SiO}_{2}$ catalyst showed a large peak at $503 \mathrm{~K}$-exactly where the $\mathrm{Pt}$ peak in $1.0 \mathrm{Pt} / \mathrm{SiO}_{2}$ appeared. In the bimetallic sample, this peak is slightly broadened owing to a contribution from the Au reduction. A shoulder at $433 \mathrm{~K}$ is also visible-probably due to the lowtemperature $\mathrm{Au}$ reduction. The $1.0 \mathrm{Pt}-0.3$ $\mathrm{Au} / \mathrm{SiO}_{2}$ TPR results indicate that there is very little interaction between the $\mathrm{Pt}$ and Au components as there are no peak shifts and the plot of the bimetallic catalyst appears to be merely the sum of the TPR profiles of the monometallic components.

The $1.0 \mathrm{Pt}-0.7 \mathrm{Au} / \mathrm{SiO}_{2}$ bimetallic catalyst, in contrast, shows two peaks, a large narrow region centered at $493 \mathrm{~K}$ and a smaller peak at $433 \mathrm{~K}$. In comparing this profile with that of $1 \mathrm{Pt} / \mathrm{SiO}_{2}$ it can be inferred that the shift of the platinum reduction peak is caused by an interaction with the Au component. This in turn implies that the Pt and Au entities in this catalyst are in intimate contact with each other possibly in the form of the alloy $\mathrm{Au}_{3} \mathrm{Pt}$ or as a $\mathrm{Pt}-\mathrm{Au}$ cluster. The TPR profiles reinforce the notion that there are big differences among the various catalysts.

\section{Microstructural Characterization by Electron Microscopy}

To gain further insight into these differences, extensive electron microscopy characterization was performed spanning the entire particle size range on each sample. Figure 3 shows transmission electron micrographs of the four catalyst samples with the corresponding histograms (Fig. 4) illustrating the size distributions of metal crystallites. One has to be aware that the transmission micrographs show two dimensional projections of metal crystallites, and there is no definite way of extrapolating the true three-dimensional shape of a particle. For 

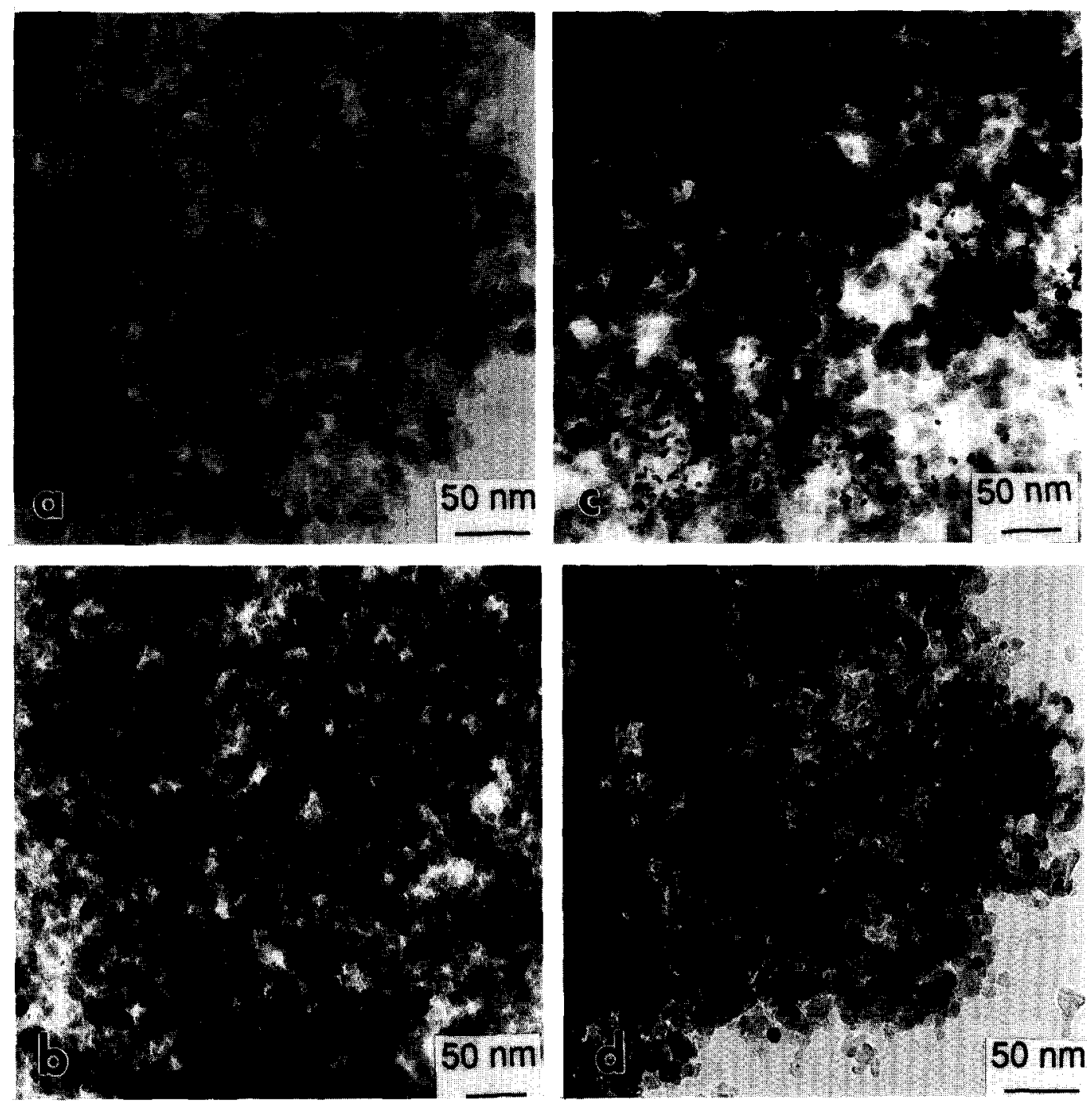

Fig. 3. Representative low-magnification micrographs from the four catalysts: (a) $1.0 \mathrm{Pt} / \mathrm{SiO}_{2}$, (b) 2.0 $\mathrm{Au} / \mathrm{SiO}_{2}$, (c) $1.0 \mathrm{Pt}-0.3 \mathrm{Au} / \mathrm{SiO}_{2}$, (d) $1.0 \mathrm{Pt}-0.7 \mathrm{Au} / \mathrm{SiO}_{2}$.

determining the size of a given particle, the average between the longest and the shortest diameter of its two-dimensional projection was used. The $\mathrm{Pt} / \mathrm{SiO}_{2}$ catalyst, for example, had a particle size range from 0.5 to $16 \mathrm{~nm}$ with a mean at $3.7 \pm 0.3 \mathrm{~nm}$ whereas the bimetallic $1 \mathrm{Pt}-0.3 \mathrm{Au} / \mathrm{SiO}_{2}$ catalyst had a much wider size range from 0.5 to $40 \mathrm{~nm}$.

A thorough examination of the entire particle size range in a given supported catalyst can shed a great deal of light on the reasons behind particular activity and se- lectivity trends as a function of overall composition. In the case of bimctallic catalysts, an additional complication arises. One has to now establish how the various components are allocated to crystallites as a function of the particle size distribution. This can be accomplished within the microscope by EDX analysis of individual metal crystallites falling into different size classifications. In this technique, the energies of characteristic X-rays emitted from small regions of the sample are measured. The im- 

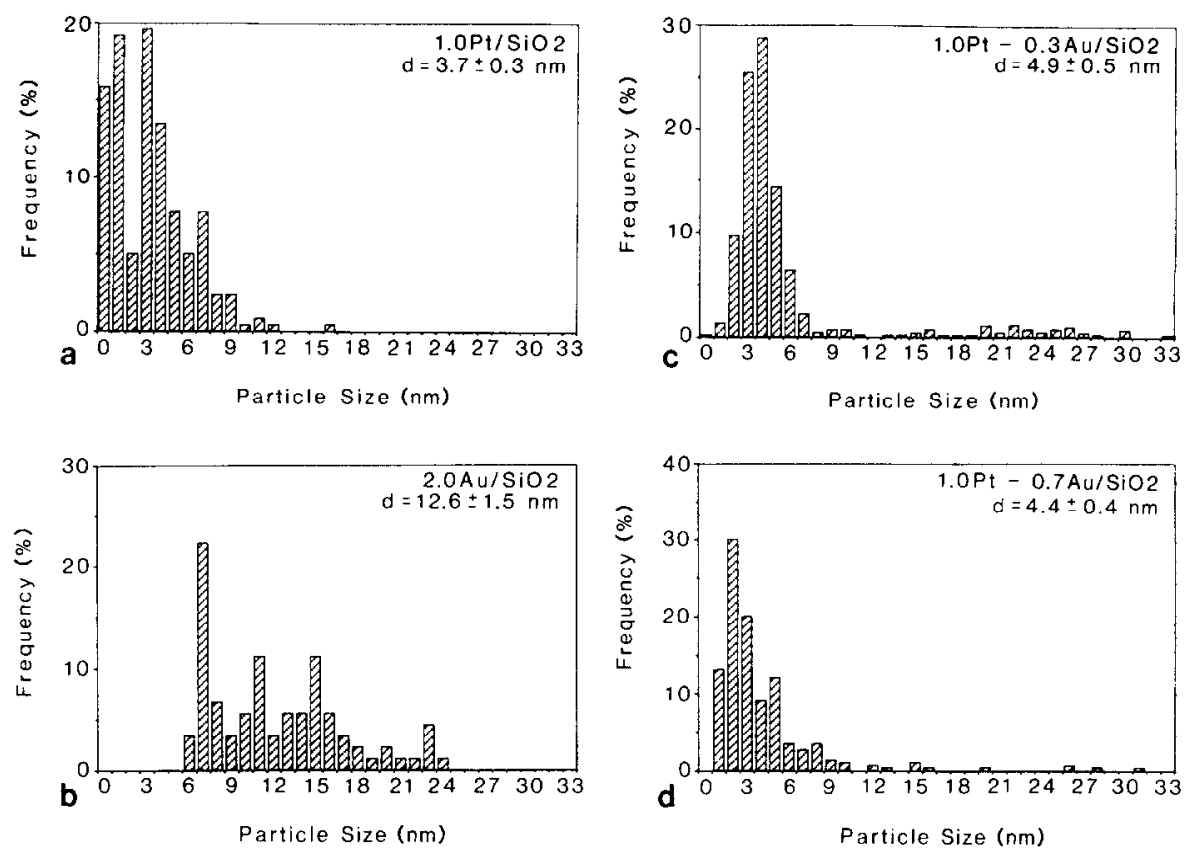

FIG. 4. Particle size distributions from (a) $1.0 \mathrm{Pt} / \mathrm{SiO}_{2}$, (b) $2.0 \mathrm{Au} / \mathrm{SiO}_{2}$, (c) $1.0 \mathrm{Pt}-0.3 \mathrm{Au} / \mathrm{SiO}$, (d) 1.0 $\mathrm{Pt}-0.7 \mathrm{Au} / \mathrm{SiO}_{2}$. Note: the presence of metallic aggregates in the $0.7 \mathrm{Au}$ catalyst could not be taken into account in this particle size distribution.

portance of this type of analysis has been vividly illustrated in the case of $\mathrm{Ru}-\mathrm{Au} /$ $\mathrm{SiO}_{2}$ catalysts, where bimetallic $\mathrm{Ru}-\mathrm{Au}$ particles existed only in a size range smaller than $5 \mathrm{~nm}$ while particles larger than $10 \mathrm{~nm}$ were without exception monometallic $\mathrm{Au}$ particles $(2,17)$. For the partially miscible $\mathrm{Pt}-\mathrm{Au}$ system, the additional question of ordered alloy formation versus mere bimetallic aggregate formation needs to be addressed. The answer to this question can be provided by structure images obtained in HREM.

In the past, high-resolution electron microscopy studies exploiting the full range of capabilities of a modern analytical and high-resolution microscope were able to give insight into the microstructure of very small metal particles (less than $5 \mathrm{~nm}$ in diameter). Many of these studies have been performed on model samples which were more amenable to microscopic imaging and characterization. Typically, specimens for these kinds of studies were prepared by vacuum evaporation of small metal particles onto the surface of amorphous oxide substrates. Recently, metal particles on very uniform, low-surface-area model supports have been tested catalytically as well as characterized by electron microscopy. These types of studies have given valuable insight into the particle shape, structure, and wetting characteristics on the support. They also very elegantly illustrated the presence of oxidic overlayers on Rh metal particles supported on $\mathrm{TiO}_{2}(18)$.

Although such model studies play an important role in unraveling the nature and structure of small metal particles, it is desirable to apply an extensive arsenal of microscopic characterization techniques to industrial-type supported catalysts where realistic tests of their catalytic activity can readily be made. Our study extends the powerful array of microscopic techniques to a series of bimetallic catalysts supported on high-surface-area $\mathrm{SiO}_{2}$. The main purpose of this paper is to correlate the micros- 


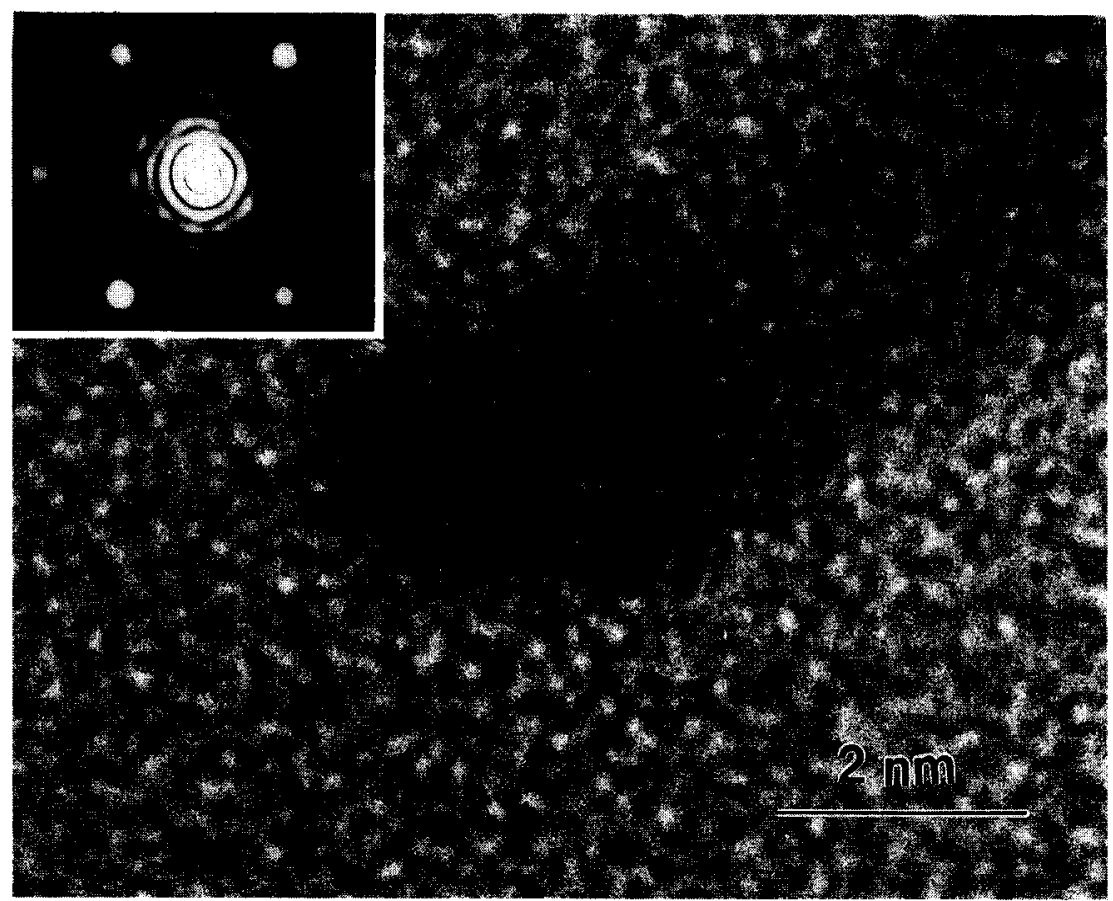

FIG. 5. High-resolution electron micrograph of a typical particle from the monometallic $1.0 \mathrm{Pt} / \mathrm{SiO}_{2}$ catalyst. Inset: An optical diffraction pattern from the particle indicating the $\mathrm{Pt}(111)$ and $\mathrm{Pt}(200)$ planes with spacings of 0.227 and $0.196 \mathrm{~nm}$, respectively.

copy results with activity and selectivity patterns, while a more detailed discussion of the microscopy techniques will be published elsewhere (19).

(3.1) $1.0 \mathrm{Pt} / \mathrm{SiO}_{2}$. The particle sizes in this monometallic platinum catalyst range from 0.5 to $16 \mathrm{~nm}$. From particles larger than $6 \mathrm{~nm}$ it is feasible to obtain microdiffraction patterns by using the small stationary electron probe in the analytical microscope. There are no consistent crystallite shape patterns which emerge from the micrographs although there are a few "peanut" shaped or polyparticles visible. These shapes probably arose when two adjacent small particles fused together during the high-temperature reduction. The nonporosity of the silica support might also have contributed to the peculiar shapes of some of the particles.

A typical high-resolution electron microscopy image of a platinum particle is shown in Fig. 5 along with the correspond- ing optical diffraction pattern. The Pt(111) and $\mathrm{Pt}(200)$ planes with spacings of 0.227 and $0.196 \mathrm{~nm}$, respectively $(20)$, are the only two lattice planes which can be successfully imaged within the resolution limits of the microscope. The other spacings are less than $0.14 \mathrm{~nm}$ which is below the line to line resolution of the $400-\mathrm{kV}$ instrument. The microanalysis of localized regions by lattice imaging and the relative errors associated with this technique have been discussed by Sinclair and Thomas (21).

One of the factors that must be taken into consideration in interpreting the lattice spacings is the possibility of lattice expansion and contraction in the regime of small particles with diameters of $2 \mathrm{~nm}$ or less. Heinemann and Poppa (22) found an expansion of $2.9 \%$ in the 1 - to $2-\mathrm{nm}$ size range of palladium particles supported on mica. They attributed this expansion as most likely due to the transformation of the $\mathrm{Pd}$ 
particles from a composite crystal, conceivably an icosahedral structure, to that of the bulk fcc configuration. These authors also considered the effect of a pseudomorphic influence between the support and the metal particle. Other potential contributions to the lattice expansions and contractions could come from surface stress due to the high surface-to-volume ratio of small particles. Jacobs and Schryvers (23) also measured increasing lattice expansions in the (111) planes of palladium particles photodeposited on titania films after oxidative treatments.

For the case of platinum, numerous studies (24-26) have reported that the monocrystalline structure is maintained down to very small sizes with no measured lattice spacing changes. This is in agreement with high-resolution electron microscopy studies of "real" as well as model platinum/ alumina catalysts. There, it was observed that platinum crystallites down to $1 \mathrm{~nm}$ maintained the bulk fcc structure $(27,28)$. In contrast, however, Solliard and Flueli (29) reported a decrease in the lattice parameter proportional to the reciprocal of the platinum particle size and attributed this to surface stress effects. In agreement with the previous high-resolution studies $(27,28)$ we find no deviation from the bulk fec values in the lattice spacings of our $1 \mathrm{Pt} /$ Aerosil in particles down to about $1 \mathrm{~nm}$. But, this was not true for all crystallites in the subnanometer range. Figure 6 shows a cluster of platinum particles in the size range of about $1 \mathrm{~nm}$ or less and the accompanying optical diffraction pattern from one of the particles indicating a change in the lattice parameter. At these subnanometer sizes, particles of fcc metals tend to assume more stable configurations which result in icosahedral or decahedral type symmetries (30). As even for monometallic particles

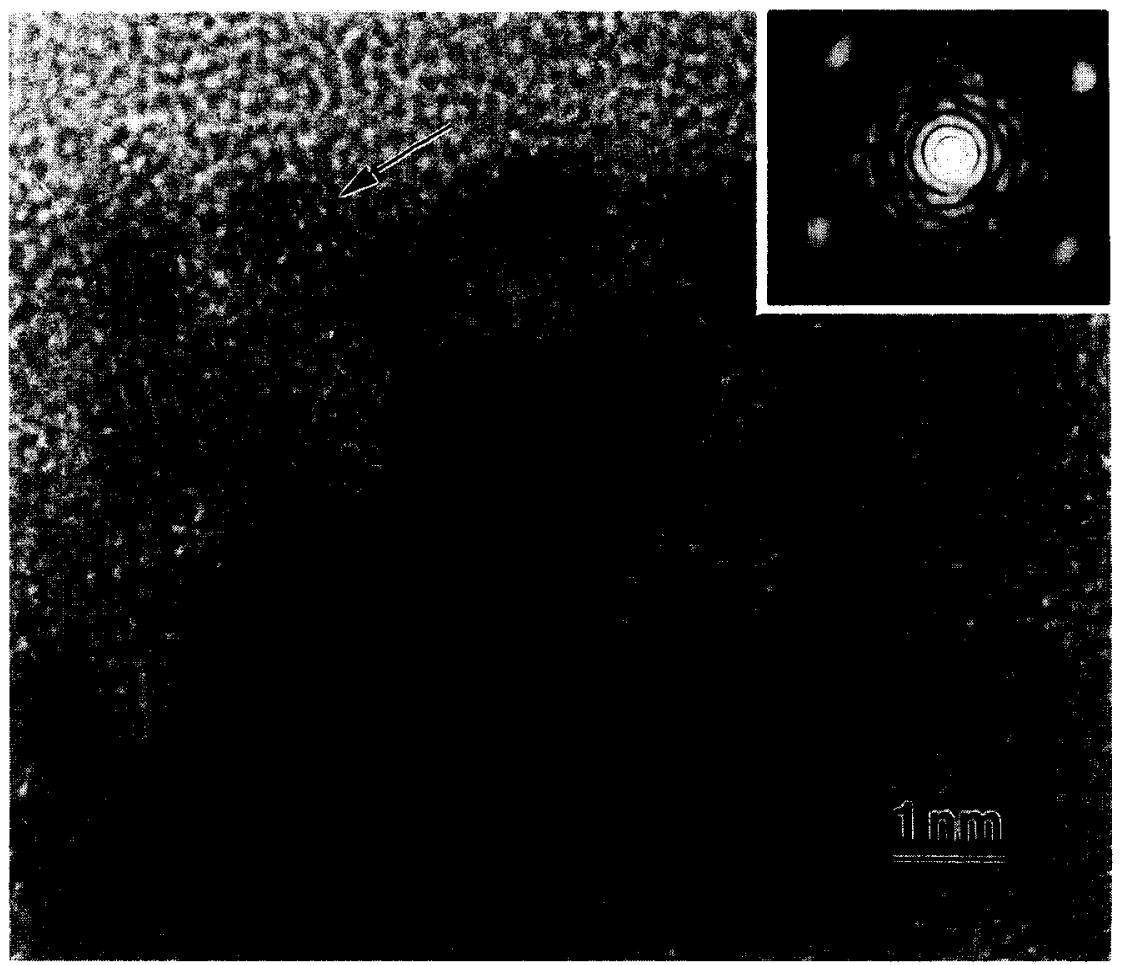

FIG. 6. A HREM image of a cluster of small platinum particles from the monometallic $1.0 \mathrm{Pt} / \mathrm{SiO}_{2}$ catalyst. The corresponding optical diffraction pattern from a subnanometer particle (arrow) indicates a non-fcc structure. 
such large changes in lattice parameter occur, the identification of the composition and phase of bimetallic particles smaller than $1 \mathrm{~nm}$ by HREM cannot be considered reliable.

(3.2) $2.0 \mathrm{Au} / \mathrm{SiO}_{2}$. The gold particles on silica had, as expected, a large mean particle size of $12.6 \mathrm{~nm}(31)$. As opposed to platinum, gold has been found to undergo contraction of the lattice parameter by about $1 \%$ in particles about $10-50 \mathrm{~nm}$ in diameter (22). Even though the particles in our 2.0 $\mathrm{Au} / \mathrm{SiO}_{2}$ catalyst fall into approximately this size range, there were no significant discrepancies measured from the bulk fcc values of the $\mathrm{Au}(111)$ and $\mathrm{Au}(200)$ lattice spacings which are 0.235 and $0.205 \mathrm{~nm}$, respectively (32). Figure 7a shows a HREM image and the optical diffraction pattern of a typical gold crystal. A certain fraction of the gold particles exhibited the so-called multiply twinned structure (30). The decahedral particle in Figure $7 \mathrm{~b}$ shows the $\mathrm{Au}(111)$ lattice fringes with spacings of $0.235 \mathrm{~nm}$.

(3.3) Bimetallic $1 \mathrm{Pt}-0.3 \mathrm{Au} / \mathrm{SiO}_{2}$. A major complication in interpreting the highresolution images of these bimetallic catalyst particles is the similarity in the lattice parameters of platinum with the $\mathrm{Au}_{3} \mathrm{Pt}$ alloy. The (111) and (200) spacings of fcc platinum are nearly identical to that of the tetragonal $\mathrm{Au}_{3} \mathrm{Pt}$ (33) and this makes it virtually impossible to differentiate the structure image of one from the other. In a previous study of colloidally prepared platinum-gold particles the presence of $\mathrm{Pt}-\mathrm{Au}$ alloys was inferred from a statistical analysis of the lattice spacings (34). The procedure undertaken by us to overcome this complication involved the elemental mapping by EDX of the various particle size ranges in the specimen. Here, too, the proximity of the gold and platinum peaks for most regions of the X-ray spectrum makes it difficult to separate one from the other. However, the X-ray peaks in the L region of the spectrum provide enough separation between platinum and gold to allow one to gain at least a qualitative estimate of the relative amounts of the two elements within the desired specimen region.

Figure 8 shows two regions from this bimetallic sample imaged under high-resolution conditions. These two regions correspond to relatively thin areas of the sample. It was very difficult to acquire structure images from thicker areas $(>10 \mathrm{~nm})$ of the specimen. The particle size distribution of this catalyst, including particle sizes up to $35 \mathrm{~nm}$, is much wider than that of the monometallic $\mathrm{Pt} / \mathrm{SiO}_{2}$. Almost all of the images taken at high resolution were of particles 10 $\mathrm{nm}$ or less. All the particles in this size range, without exception, had lattice spacings of 0.227 and $0.196 \mathrm{~nm}$. These distances, as has been previously stated, can correspond to either elemental platinum or to the $\mathrm{Au}_{3} \mathrm{Pt}$ alloy. No evidence of elemental gold was found in any of the HREM micrographs. This finding was confirmed, albeit indirectly, by EDX (Fig. 9). The characteristic X-rays emitted from all crystallites less than about $20 \mathrm{~nm}$ indicated the presence of only elemental platinum (Fig. 9a). On the other hand, crystallites larger than this were mostly pure gold. With this information it can be postulated that most of the smaller particles imaged at high resolution, as well as those between 10 and 20 $\mathrm{nm}$, were mostly pure platinum while even larger sizes can mainly be attributed to elemental gold (Fig. 9b). No evidence was found for the presence of the $\mathrm{Au}_{3} \mathrm{Pt}$ alloy or for the formation of Pt-Au bimetallic clusters.

(3.4) $1.0 \mathrm{Pt}-0.7 \mathrm{Au} / \mathrm{SiO}_{2}$. The particle size distribution in this catalyst, shown in Fig. 4d, is similar to the $0.3 \mathrm{Au}$ catalyst; however, this might be somewhat misleading as there were regions in this catalyst which showed particle agglomeration. The lattice spacings in the HREM images (see Fig. 10), like the $0.3 \mathrm{Au}$ catalyst, showed almost without exception the presence of clemental platinum or of the $\mathrm{Au}_{3} \mathrm{Pt}$ alloy in the small particle region. But, unlike the 0.3 Au sample, the EDX spectra consistently 

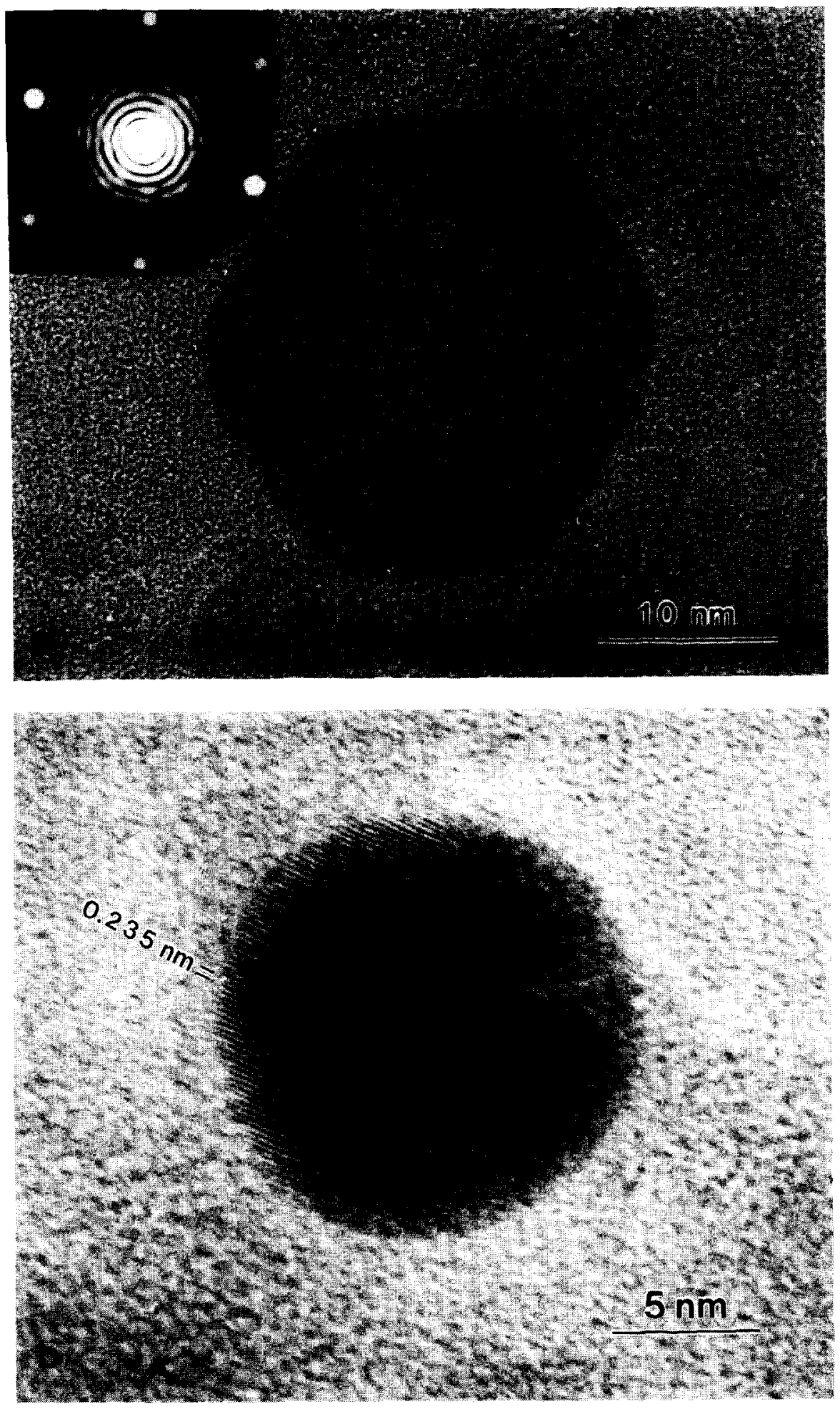

FIG. 7. (a) A high resolution micrograph from a 20 -nm gold particle from monometallic $2.0 \mathrm{Au} / \mathrm{SiO}_{2}$. Inset: The optical diffraction pattern indicates a fcc structure with $\mathrm{Au}(111)$ and $\mathrm{Au}(200)$ spacings of 0.235 and $0.205 \mathrm{~nm}$, respectively. (b) A multiply twinned particle (MTP) of gold with decahedral symmetry. 

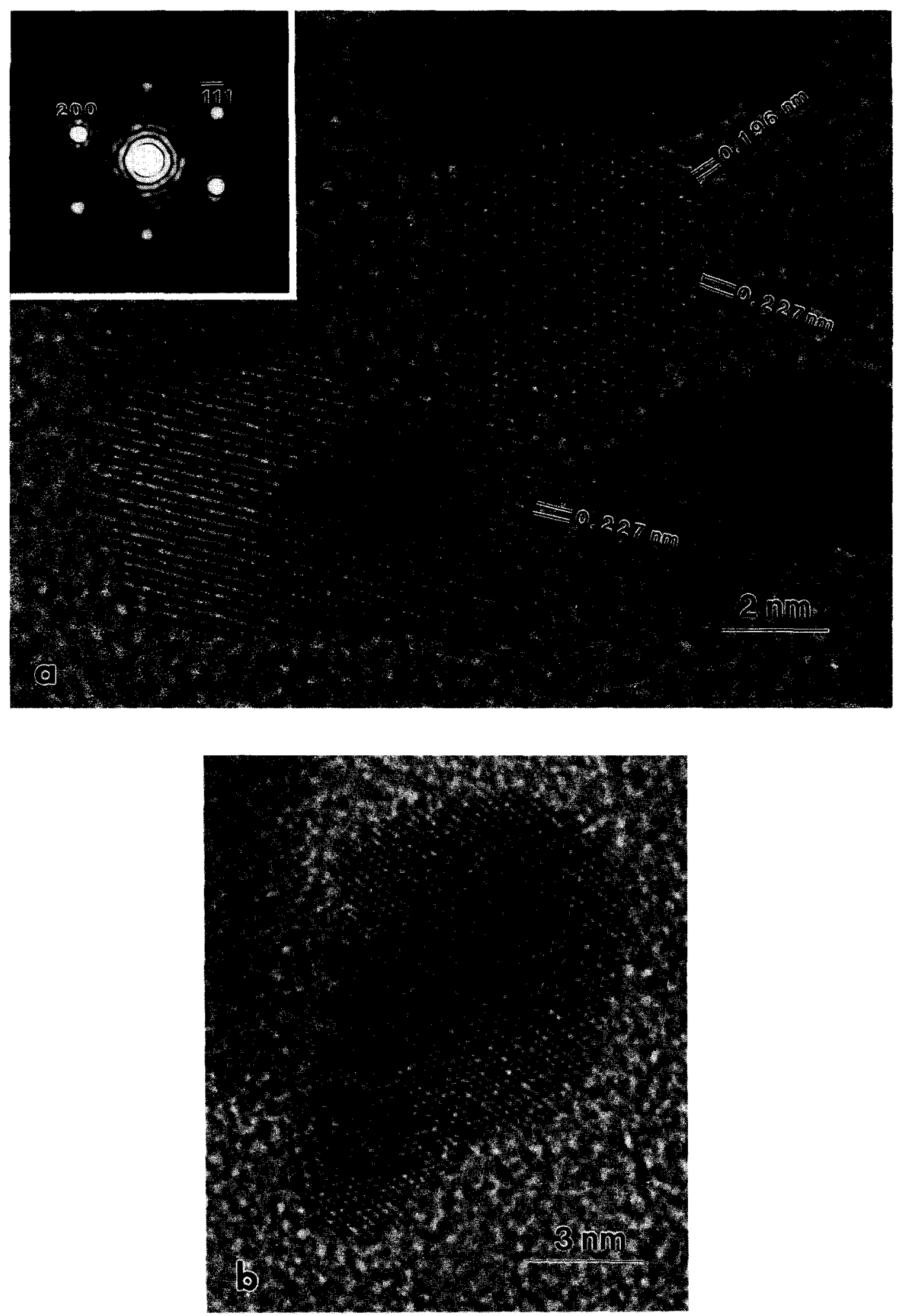

FIG. 8. HREM images from the bimetallic $1.0 \mathrm{Pt}-0.3 \mathrm{Au} / \mathrm{SiO}_{2}$ catalyst. The optical diffraction pattern (inset) of the particles in these images has $d$ spacings indicating the presence of either platinum or $\mathrm{Au}_{3} \mathrm{Pt}$ alloy. Particle in Fig. $8 \mathrm{~b}$ shows evidence of inhomogeneous strain. 
indicated the coexistence of $\mathrm{Pt}$ and $\mathrm{Au}$ in lites ranging from 3 to $5 \mathrm{~nm}$. Knowing that virtually the entire particle size distribu- the HREM imaged particles could either be tion. Figure $9 \mathrm{c}$ shows the EDX spectrum pure $\mathrm{Pt}$ or $\mathrm{Au}_{3} \mathrm{Pt}$ and also learning from taken from a cluster of five adjacent crystal- EDX that platinum and gold coexist in
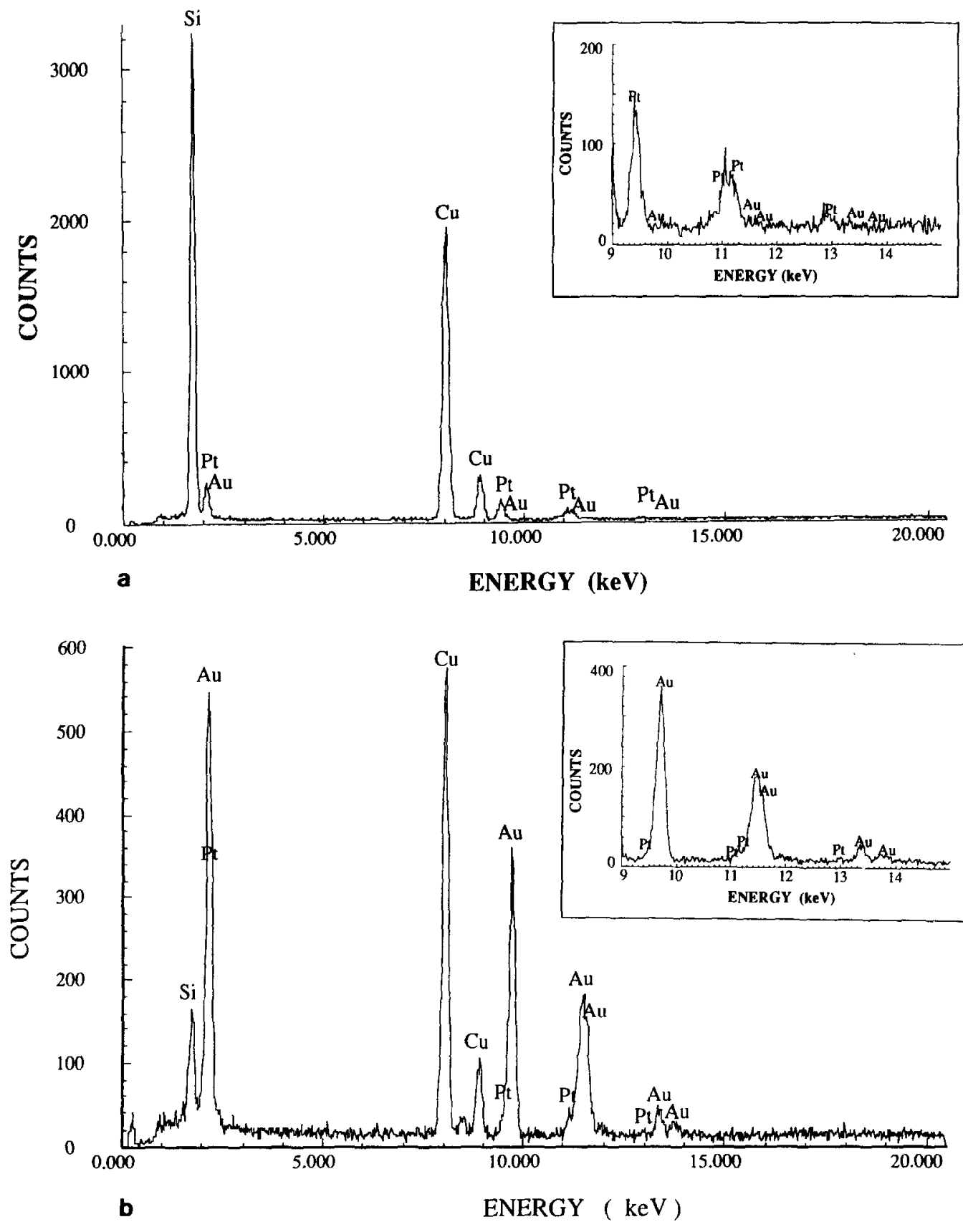

FIG. 9. Representative EDX spectra from the bimetallic catalysts. Inset: X-ray peaks in the $\mathrm{L}$ region. (a) Platinum only small-particle region in $1.0 \mathrm{Pt}-0.3 \mathrm{Au} / \mathrm{SiO}_{2}$. (b) Spectrum from a large particle $(30 \mathrm{~nm})$ in $1.0 \mathrm{Pt}-0.3 \mathrm{Au} / \mathrm{SiO}_{2}$ showing only gold peaks. (c) Region in $1.0 \mathrm{Pt}-0.7 \mathrm{Au} / \mathrm{SiO}_{2}$ showing the presence of both platinum and gold. 


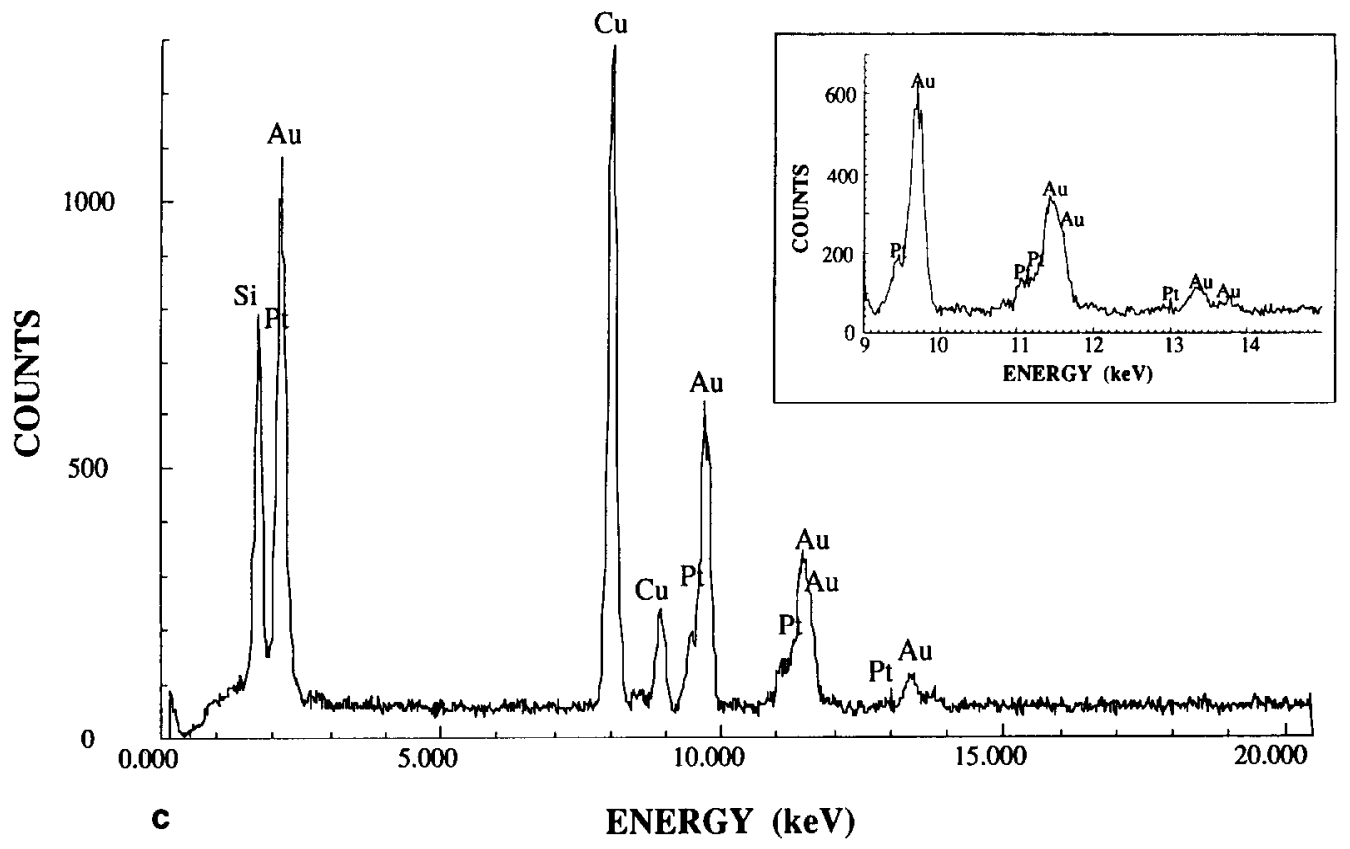

FIG. 9-Continued.

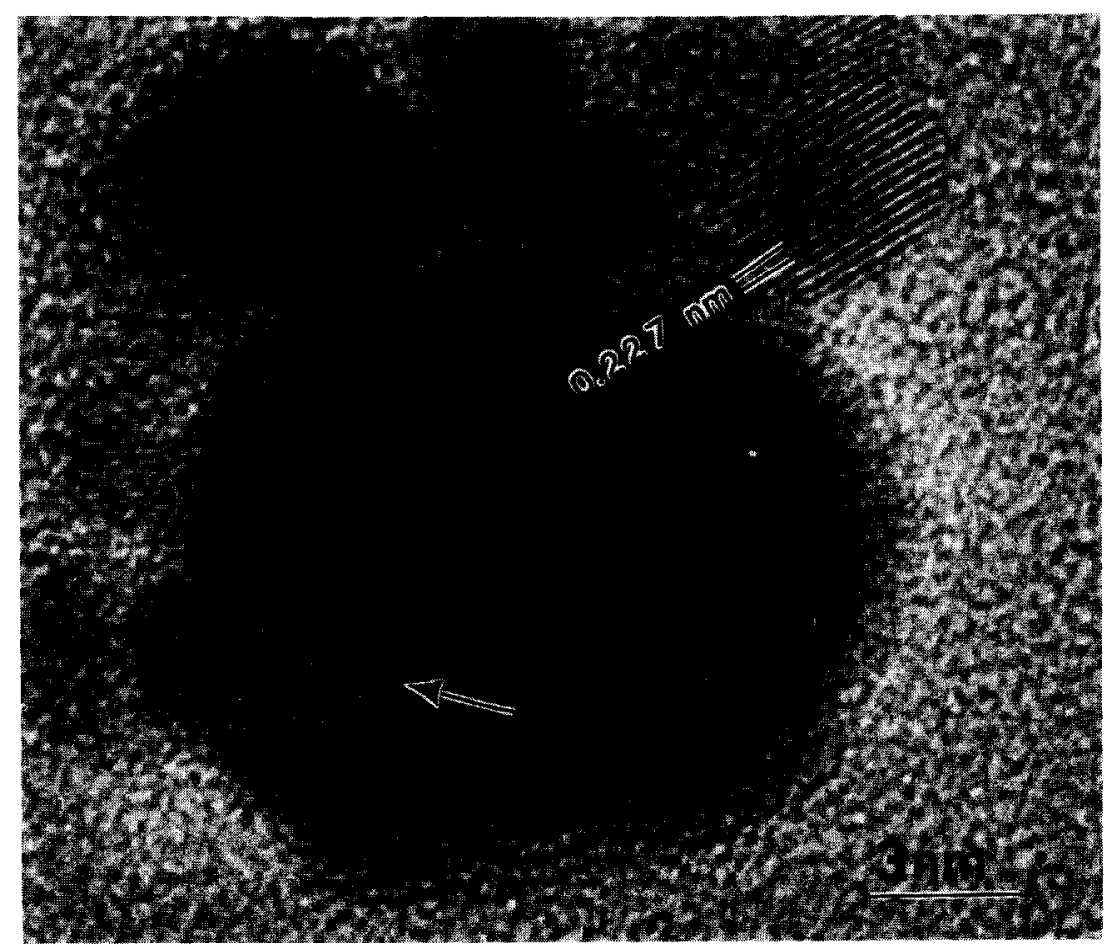

FIG. 10. Cluster of particles from 1.0 Pt-0.7 $\mathrm{Au} / \mathrm{SiO}_{2}$. Arrowed particle has unknown composition and appears to possess an icosahedral symmetry. 
small particles, it can be inferred that some alloy species are present at least in the small particle region. It cannot be ruled out, however, that there could also be a few monometallic platinum particles as they cannot be individually differentiated from the $\mathrm{Pt}-\mathrm{Au}$ alloy. Coincidentally, the gold peak in the EDX spectra also consistently showed an intensity about three times that of the platinum peak. This ratio could correspond to the relative amounts of $\mathrm{Au}$ and $\mathrm{Pt}$ in an $\mathrm{Au}_{3} \mathrm{Pt}$ alloy, but $\mathrm{Au}$ enrichment in $\mathrm{Pt}-\mathrm{Au}$ particles cannot be ruled out. Although both platinum and gold were detected in the large particles and aggregates, it cannot be said with any certainty that the alloy exists here since lattice images could not be obtained.

The X-ray diffraction analysis of this catalyst did detect a small amount of elemental gold. From this it can be deduced that not all the gold is in the Pt-Au alloys and some of it could either be within a bimetallic cluster or merely segregated out. In either case this gold is in the form of fairly large particles; otherwise it would not have been picked up by the X-ray scan.

\section{DISCUSSION}

It has been confirmed by EDX and HREM that in the $0.3 \mathrm{Au}$ catalyst most particles smaller than $20 \mathrm{~nm}$ are elemental $\mathrm{Pt}$ and that $\mathrm{Au}$ is present only at the high end of the particle size range. The conclusion that the platinum and the gold in this catalyst were segregated could also be inferred from the TPR profiles. There, the lack of peak shifts as well as the appearance of the spectrum as being merely the sum of its monometallic components strongly support this contention. The presence of the large Pt particles probably causes the isomerization reaction to go through a bond shift mechanism sometimes also referred to as the Anderson-Avery mechanism $(13,35)$. Normally, a fraction of the intermediate species formed in this mechanism is eventually converted to cracked products. Such large $\mathrm{Pt}$ particles are absent in the monome- tallic $\mathrm{Pt} / \mathrm{SiO}_{2}$ catalyst. Therefore, one would expect the isomerization on monometallic platinum to proceed via the cyclic intermediate route typically found on smaller Pt particles (13). Some of these intermediates are known to undergo conversion to cyclic compounds. This explains the higher cyclization and lower cracking selectivities of the monometallic $\mathrm{Pt} / \mathrm{SiO}_{2}$ as opposed to the $0.3 \mathrm{Au}$ bimetallic catalyst.

The $0.7 \mathrm{Au}$ catalyst, on the other hand, has small particles $(<10 \mathrm{~nm})$ which have been found to consist primarily of the $\mathrm{Au}_{3} \mathrm{Pt}$ phase. This close proximity of gold and platinum leads to a decrease in the average platinum ensemble size. Consequently, the reaction selectivity favors the formation of the isomeric products. Although EDX analysis indicated the presence of both platinum and gold in the large particles as well as metallic aggregates, it was not determined whether alloys do indeed exist in these large particles and aggregates. Whether or not the $\mathrm{Au}_{3} \mathrm{Pt}$ alloy phase is formed in this size range, it can nevertheless be concluded that the platinum and gold are in close proximity of each other. $\mathrm{X}$-ray diffraction and gas chemisorption studies (36) have determined that a silica supported $\mathrm{Pt}-\mathrm{Au}$ catalyst possibly contained aggregates of platinum and gold atoms as well as Au atoms only. It was hypothesized that the formation of these aggregates began with separate platinum and gold nucleation sites on the support. Subsequently, due to the higher mobility of the Au particles, deposition of some gold on the surface of the platinum is conceivable. Also, the TPR profiles of our $0.7 \mathrm{Au}$ catalyst support the postulation that $\mathrm{Pt}-\mathrm{Au}$ alloys are present to a certain extent. Taking all the information from TPR and the microstructural characterization into account, the selectivity trend toward higher isomerization and lower cracking can be readily interpreted. This type of characterization strategy correlating particle microstructure and composition with activity and selectivity could possibly help explain the 
apparent contradictions in the catalytic behavior of $\mathrm{Pt}-\mathrm{Au}$ catalysts studied by Clarke et al. (16). With the lack of large ensembles of platinum sites available the reaction mechanism of choice for the formation of isomeric products would probably be the cyclic intermediate or the one-site carbonium ion-like pathway, the latter of which proceeds only on very diluted platinum regions. This is in agreement with van Schaik et al. (13) who also reported that the largest changes in the selectivity occurred only in the region of the very diluted alloy.

The goal of this project was to characterize the microstructure of a given catalyst and correlate it with its catalytic behavior. The variation in the structure and kinetic behavior of the $0.3 \mathrm{Au}$ from the $0.7 \mathrm{Au}$ cannot be generalized for the $\mathrm{Au}-\mathrm{Pt}$ system before more work is done. The changes in microstructure and consequently the reaction behavior between these two catalysts probably arose due to subtleties in the catalyst preparation. From the case study of the $0.7 \mathrm{Au}$ catalyst we can learn an important lesson regarding the composition of small metal particles: even in bimetallic samples with bulk atomic ratios within the miscibility gap of the $\mathrm{Pt}-\mathrm{Au}$ phase diagram, the composition and structure of the small metal particles do not necessarily follow predictable trends. Also, it has been suggested in the literature (14) that alloys are formed in these catalysts only after repeated oxidation and reduction steps. However, we see evidence of alloy formation even though the only pretreatment undergone by this catalyst was a $673-\mathrm{K}$ hydrogen reduction. The presence of equilibrated two-phase well-mixed alloy particles is known to facilitate isomerization, while lowering the selectivity for hydrogenolytic cracking. Such selectivity patterns have also been exhibited in well-mixed and equilibrated bulk $\mathrm{Pt}-\mathrm{Au}$ alloys prepared by the Kulifay method (37).

This study has demonstrated how useful analytical and high-resolution electron microscopy can be, when used in conjunction with each other and a variety of other characterization techniques, in explaining seemingly contradictory catalytic behavior as a function of overall catalyst composition. Yet, HREM or AEM by itself would not be sufficient to fully unravel the microstructure of the metal particles. One has to proceed with caution in trying to interpret the results from these experiments due to the complexities in the sample as well as in the microscopy techniques. Ideally, one would require the microanalysis to be performed on a very large number of particles, but pains were taken to ensure that the analyzed regions were representative of the overall catalyst.

\section{SUMMARY}

1. The selectivity for the $n$-hexane conversion reactions showed an increase in isomerization for the $1.0 \mathrm{Pt}-0.7 \mathrm{Au} / \mathrm{SiO}_{2}$ catalyst over the monometallic $\mathrm{Pt} / \mathrm{SiO}_{2}$ sample. However, the 1.0 Pt-0.3 $\mathrm{Au} / \mathrm{SiO}_{2}$ specimen had a higher cracking selectivity than the monometallic catalyst.

2. Temperature-programmed reduction profiles indicated that the platinum and gold were probably segregated from each other in the bimetallic $0.3 \mathrm{Au}$ catalyst. In contrast, evidence was found for an interaction between these two elements in the bimetallic 0.7 Au sample.

3. It was determined from EDX and HREM that the $0.3 \mathrm{Au}$ catalyst contained monometallic platinum particles up to 20 $\mathrm{nm}$ and monometallic gold crystallites in even higher size ranges. But, for the $0.7 \mathrm{Au}$ sample the elemental composition of the metal particles showed that platinum and gold coexisted for most of the size ranges. In conjunction with this finding and the lattice fringe images from HREM, it can be inferred that most of the smaller particles $(<10 \mathrm{~nm})$ in this catalyst have the $\mathrm{Au}_{3} \mathrm{Pt}$ composition.

4. With the presence of relatively large monometallic platinum particles in the $\mathbf{0 . 3}$ Au catalyst there might be a tendency for the isomerization reaction in the $n$-hexane 
conversion to go through a bond shift intermediate. On the other hand, in the $0.7 \mathrm{Au}$ catalyst the proximity of the gold and platinum atoms in the form of a $\mathrm{Pt}-\mathrm{Au}$ alloy or merely a bimetallic cluster probably causes the isomerization reaction to pass via a cyclic intermediate or even a carbonium ionlike mechanism.

\section{ACKNOWLEDGMENTS}

Funding for this research was provided by the National Science Foundation grant CBT-8608106. We are also grateful to Dr. John F. Mansfield of the Electron Microbeam Analysis Laboratory at The University of Michigan for assistance in analytical electron microscopy. The help of Mr. K. Balakrishnan in reaction data collection is also appreciated.

\section{REFERENCES}

I. Cowley, J. M., and Plano, R. J., J. Catal. 108, 199 (1987).

2. Datye, A. K., and Schwank, J., in "Proceedings, 8th International Congress on Catalysis, Berlin, 1984," Vol. IV, p. 587. Verlag-Chemie, Weinheim, 1984.

3. Hansen, M., in "Constitution of Binary Alloys." McGraw-Hill, New York, 1958.

4. Sachtler, J. W. A., and Somorjai, G. A., J. Catal. 81, 77 (1983).

5. Stephen, J. J., Ponec, V., and Sachtler, W. M. H., Surf. Sci. 47, 403 (1975).

6. Foger, K., and Anderson, J. R., Appl. Surf. Sci. 2, 335 (1979).

7. Hörnström, S. E., Johansson, L. 1., and Flödström, A., Appl. Surf. Sci. 26, 27 (1986).

8. Tsong, T. T., Ng, Y. S., and McLane, S. B., $J$. Chem. Phys. 73, 1464 (1980).

9. Schwartz, J. A., Polizzotti, R. S., and Burton, J. J., I. Vac Sri. Terhnol. 14, 457 (1977).

10. Ponec, V., and Sachtler, W. M. H., in "Proceedings, 5th International Congress on Catalysis, Palm Beach, 1972' (J. W. Hightower, Ed.), Vol. 1, p. 645. North-Holland, Amsterdam, 1973.

II. Sachdev, A., and Schwank, J., in "Proceedings, 9th International Congress on Catalysis, Calgary, 1988' (M. J. Phillips and M. Ternan, Eds.), Vol. 3, p. 1275. Chem. Institute of Canada, Ottawa, 1988.

12. Yeates, R. C., and Somorjai, G. A., J. Catal 103, 208 (1987).
13. van Schaik, J. R. H., Dessing, R. P., and Ponec, V., I. Catal. 38, 273 (1975)

14. O'Cinneide, A., and Gault, F. G., J. Catal. 37, 311 (1975).

15. McKervey, M. A., Rooney, J. J., and Samman. N. G., J. Catal. 30, 330 (1973).

16. Clarke, J. K. A., Manninger, I., and Baird, T., J. Catal. 54, 230 (1978).

17. Shastri, A. G., and Schwank, J., J. Catal. 98, 191 (1986).

18. Braunschweig, E. J., Logan, A. D., and Datye, A. K., in "Proceedings of the Material Research Society, Boston" (M. M. J. Treacy, J. M. Thomas, and J. M. White, Eds.), Vol. 111. Pittsburgh, PA (1987).

19. Sachdev, A., PhD dissertation, The University of Michigan, 1989.

20. ASTM, X-Ray Powder Data File 4-802.

21. Sinclair, R., and Thomas, G., Metall. Trans, A 9, 373 (1978)

22. Heinemann, K., and Poppa, H., Surf. Sci. 156, 265 (1985).

23. Jacobs, J. W. M., and Schryvers, D., J. Catal. 103, 436 (1987).

24. Turkevitch, J., Ban, L. L., and Wall, J. H., in "Perspectives in Catalysis in Commemoration of Jons Jacob Berzelius" (R. Larrson, Ed.), p. 59. Univ, of Lund, Sweden, 1979.

25. Yacaman, M. J., and Dominguez, J. M., Surf. Sci. 87, L263 (1979).

26. Solliard, C., Surf. Sci. 106, 58 (1981).

27. White, D., Baird, T., Fryer, J. R., Freeman, L. A., Smith, D. J., and Day, M., J. Catal. 81, 119 (1983).

28. Smith, D. J., White, D., Baird, T., and Fryer, J. R., J. Catal. 81, 107 (1983).

29. Solliard, C., and Flueli, M., Surf. Sci. 156, 487 (1985).

30. Marks, L. D., and Smith, D. J., J. Cryst. Growth 54, 425 (1981)

31. Fukushima, T., Galvagno, S., and Parravano, G., J. Catal. 57, 177 (1979).

32. ASTM, X-Ray Powder Data File 4-784.

33. ASTM, X-Ray Powder Data File 15-43.

34. Miner, R. S., Namba, S., and Turkevich, J., in "Proceedings, 7th International Congress on Catalysis, Tokyo, 1980" (T. Seiyama and K. Tanabe, Eds.), Vol. 7, p. 160. Elsevier, Amsterdam, 1981.

35. Anderson, J. R., and Avery, N. R., J. Catal. 7, 315 (1967).

36. Galvagno, S., and Parravano, G., J. Catal. 57, 272 (1979).

37. Kulifay, S. M., J. Amer. Chem. Soc. 83, 4916 (1961). 